Military Technical College

Kobry Elkobbah,

Cairo, Egypt

May 29-31,2012 $6^{\text {th }}$ International Conference on Mathematics and

Engineering Physics (ICMEP-

6)

\title{
On L(2,1) and Prime cordial labelings
}

\author{
M. A. Seoud ${ }^{\text {a }}$, G. M. Abd ElHamid ${ }^{\text {b }}$ and M. S. Abo Shady ${ }^{\text {c }}$ \\ ${ }^{a}$ Department of Mathematics, Faculty of Science, Ain Shams University, Abbassia, Cairo, Egypt \\ ${ }^{b, c}$ Department of Mathematics, M.T.C., Kobry ElKobba, Cairo, Egypt
}

\begin{abstract}
An $\mathrm{L}(2,1)$-labeling of a graph $G$ is a function $f$ from the vertex set $V(G)$ into the set of nonnegative integers such that $|f(x)-f(y)| \geq 2$ if $d(x, y)=1$ and $|f(x)-f(y)| \geq 1$ if $d(x, y)=2$, where $d(x, y)$ denotes the distance between $x$ and $y$ in $V(G)$. The $\mathrm{L}(2,1)$-labeling number, $\lambda(G)$, of $G$ is the minimum $k$ where $G$ has an $\mathrm{L}(2,1)$-labeling $f$ with $k$ being the absolute difference between the largest and smallest image points of $f$. A prime cordial labeling of a graph $G$ with vertex set $V$ is a bijection $f$ from $V$ to $\{1,2, \ldots,|V|\}$ such that if each edge $u v$ is assigned the label 1 if $\operatorname{gcd}(f(u), f(v))=1$ and 0 if $\operatorname{gcd}(f(u), f(v))>1$, then the number of edges labeled with 0 and the number of edges labeled with 1 differ by at most 1 . In this paper we find the labeling number $\lambda(G)$ for some families of graphs, and we give an upper bound for the number of edges of any graph on $n$ vertices to have a prime cordial labeling, and we compare this upper bound with the number of edges of two families of graphs.
\end{abstract}

Keywords: L(2, 1)-labeling, prime cordial labeling, $\mathrm{C}^{++}$programming Language

\section{Introduction}

By a graph $\mathrm{G}$ we mean a finite, undirected, connected graph without loops or multiple edges. We denote by $n$ and $m$ the order and size of the graph $G$. Terms not defined here are used in the sense of Harary [2].

\section{L(2,1) labeling}

\subsection{Background [4]}

In 1991, Roberts proposed a variation of the frequency assignment problem in which "close" transmitters must receive different frequencies and "very close" transmitters must receive frequencies that are at least two units apart. To translate the problem into the language of graph theory, the transmitters are represented by the vertices of a graph. Two vertices are "very close" if they are adjacent and "close" if they are at distance 2 in the graph. Along this direction, Yeh and afterwards Griggs and Yeh proposed that the $L(2,1)$-labeling of a simple graph $G$ is a function $f$ from the vertex set $V(G)$ into the nonnegative integers such that $|f(x)-f(y)| \geq 2$ if $d(x, y)=1$ and $|f(x)-f(y)| \geq 1$ if $d(x, y)=2$, where $\mathrm{d}(\mathrm{x}$, y) denotes the distance between $x$ and $y$ in $V(G)$. The span of $f$ is the absolute difference between the largest assigned label and the smallest assigned label of $V(G)$. The $L(2,1)$-labeling number of $G$, denoted 
Military Technical College

Kobry Elkobbah,

Cairo, Egypt

May 29-31,2012

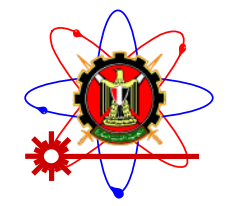

$6^{\text {th }}$ International Conference on Mathematics and

Engineering Physics (ICMEP-

6)

as $\lambda(G)$, is the minimum span taken over all $L(2,1)$-labelings of $V(G)$. Without loss of generality, we consider only those $L(2,1)$-labelings of $G$ with image that contains 0 , and we define a $k$ - $L(2,1)$-labeling of $\mathrm{G}$ to be an $L(2,1)$-labeling of $G$ which assigns no label greater than $k$. Thus, $\lambda(G)$ is the minimum $k$ such that $G$ has a $k-L(2,1)$-labeling.

An optimal solution has been provided by Griggs and Yeh [1], who labeled each vertex $i$ of a circuit of order $n$ as follows:

$$
f\left(v_{i}\right)= \begin{cases}0 & \text { if } i \equiv 0 \bmod 3 \\ 2 & \text { if } i \equiv 1 \bmod 3 \\ 4 & \text { if } i \equiv 2 \bmod 3\end{cases}
$$

However the above labeling is redefined depending on whether $n \equiv 1 \bmod 3$ or $n \equiv 2 \bmod 3$. In the first case, $f(n-4), \ldots, f(n-1)$ become

$$
f\left(v_{i}\right)=\left\{\begin{array}{l}
0 \text { if } i=n-4 \\
3 \text { if } i=n-3 \\
1 \text { if } i=n-2 \\
4 \text { if } i=n-1
\end{array}\right.
$$

In the second case, $f(n-2)$ and $f(n-1)$ are modified as

$$
f\left(v_{i}\right)= \begin{cases}1 & \text { if } i=n-2 \\ 3 & \text { if } i=n-1\end{cases}
$$

\subsection{New results}

Theorem 2.2.1: The graph $G$ with the number of vertices $n$ and the distance between any two vertices is at most two must be labeled such that at least $\lambda(G)=n-1$.

Proof: Since the maximum distance between any two vertices is two, then using $L(2,1)$-labeling, we cannot repeat any label in this graph. So, making the minimum label " 0 ", then for $n$ vertices, the maximum label will be at least $n-1$, i.e. $\lambda(G)=n-1$. An example of a graph with $n=10$ vertices and has $\lambda=9$ is shown in the following Figure. 
Military Technical College

Kobry Elkobbah,

Cairo, Egypt

May 29-31,2012



International Conference on Mathematics and

Engineering Physics (ICMEP-

6)

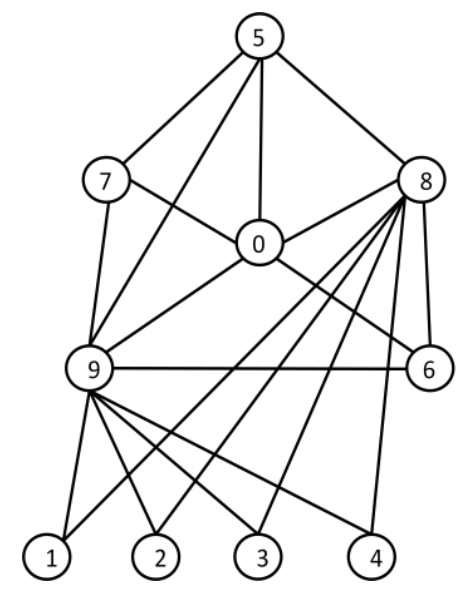

Figure 2.1: A graph with 10 vertices and $\lambda=9$

Theorem 2.2.2: The conjunction $P_{n}^{\wedge} P_{m}$ has a labeling number $\lambda=7$.

Proof: These graphs has a number of vertices $n m$ and a number of edges $2(n-1)(m-1)$. We define the following labeling function, and we see that $\lambda\left(P_{n}{ }^{\wedge} P_{m}\right)=7$ as follow:

$$
\begin{aligned}
& f\left(v_{i}^{j}\right)=\left\{\begin{array}{ll}
0, & i \equiv 0,1(\bmod 4) \\
1, & i \equiv 2,3(\bmod 4)
\end{array} \quad: j \equiv 0(\bmod 3),\right. \\
& f\left(v_{i}^{j}\right)=\left\{\begin{array}{ll}
3, & i \equiv 0,1(\bmod 4) \\
4, & i \equiv 2,3(\bmod 4)
\end{array} \quad: j \equiv 1(\bmod 3),\right. \\
& f\left(v_{i}^{j}\right)=\left\{\begin{array}{ll}
6, & i \equiv 0,1(\bmod 4) \\
7, & i \equiv 2,3(\bmod 4)
\end{array} \quad: j \equiv 2(\bmod 3) .\right.
\end{aligned}
$$

Example: $\lambda\left(P_{5} \wedge P_{8}\right)=7$ as shown in the following Figure.

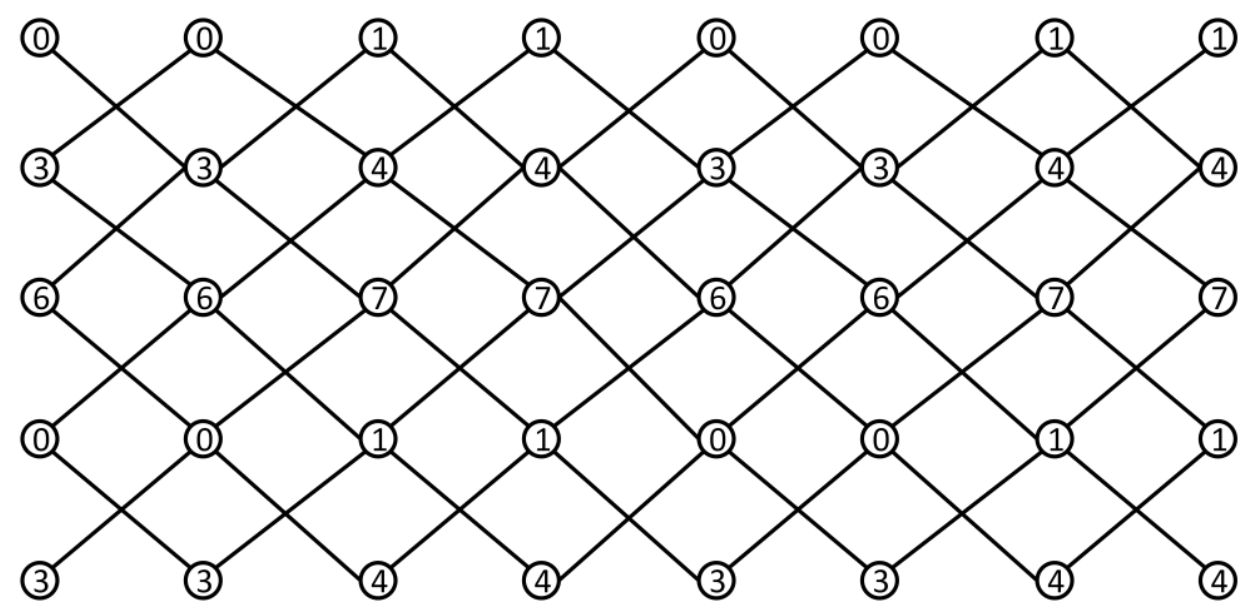

Figure 2.2: $\mathrm{L}(2,1)$ - labeling of $P_{5} \wedge P_{8}$ with $\lambda=7$ 
Military Technical College

Kobry Elkobbah,

Cairo, Egypt

May 29-31,2012

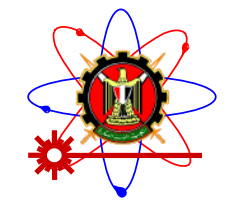

$6^{\text {th }}$ International Conference on Mathematics and

Engineering Physics (ICMEP-

6)

Definition: The triangular snake $T_{n}$ is the graph which is obtained from a path $P_{n}$ with vertices $\left\{v_{1}, v_{2}, \ldots, v_{n}\right\}$ by joining the vertices $v_{i}$ and $v_{i+1}$ to a new vertex $u_{i}$ for $i=1,2, \ldots, n-1$.

Theorem 2.2.3: The corona $T_{n} \odot K_{1}$ has the labeling number $\lambda\left(T_{n} \odot K_{1}\right)=7$.

Proof: This graph has the set of vertices $\left\{v_{1}, v_{2}, \ldots, v_{n} ; u_{1}, u_{2}, \ldots, u_{n-1} ; a_{1}, a_{2}, \ldots, a_{n} ; b_{1}, b_{2}, \ldots, b_{n-1}\right\}$. By labeling the path $P_{n}$ with the labels "0", "2" and "4", and since each vertex of the path $P_{n}$ has degree 5, so, we see that $\lambda\left(T_{n} \odot K_{1}\right)$ is at least 6 , and the vertex labeled "4" in $P_{n}$ has also five adjacent vertices which will make $\lambda\left(T_{n} \odot K_{1}\right)=7$. Then using the following labeling function we label the graph $T_{n} \odot K_{1}$.

$$
\begin{aligned}
& f\left(v_{i}\right)= \begin{cases}0, & i \equiv 1(\bmod 3) \\
2, & i \equiv 2(\bmod 3), \\
4, & i \equiv 0(\bmod 3)\end{cases} \\
& f\left(u_{i}\right)=\left\{\begin{array}{ll}
7, & i \equiv 1(\bmod 2) \\
6, & i \equiv 0(\bmod 2)
\end{array},\right. \\
& f\left(a_{i}\right)= \begin{cases}3, & i \equiv 1(\bmod 3) \\
5, & i \equiv 2(\bmod 3), \\
1, & i \equiv 0(\bmod 3)\end{cases} \\
& f\left(b_{i}\right)=\left\{\begin{array}{lll}
4, & i \equiv 1(\bmod 3) \\
0, & i \equiv 2(\bmod 3) . \\
2, & i \equiv 0(\bmod 3)
\end{array}\right.
\end{aligned}
$$

Example : $\lambda\left(T_{7} \odot K_{1}\right)=7$ as shown in the following Figure.



Figure 2.3: $\mathrm{L}(2,1)$ - labeling of $T_{7} \odot K_{1}$ with $\lambda=7$

Definition: The Sun Flower $S F(n)$ is the graph obtained from the cycle $C_{n}$ with vertices $\left\{v_{1}, v_{2}, \ldots, v_{n}\right\}$ and creating new vertices $\left\{u_{1}, u_{2}, \ldots, u_{n}\right\}$ such that $u_{i}, i=1,2, \ldots, n-1$, is connected to $v_{i}$ and $v_{i+1}$, and $u_{n}$ is connected to $v_{n}$ and $v_{1}$.

Theorem 2.2.4: The Sun Flower $S F(n)$ has the labeling number $\lambda(\operatorname{SF}(7))=7$. 
Military Technical College

Kobry Elkobbah,

Cairo, Egypt

May 29-31,2012 $6^{\text {th }}$ International Conference on Mathematics and

Engineering Physics (ICMEP-

6)

Proof: This graph has $2 n$ vertices and $3 n$ edges, the set of vertices are $\left\{v_{1}, v_{2}, \ldots, v_{n} ; u_{1}, u_{2}, \ldots, u_{n}\right\}$. Using the labeling function of circuits as defined in section 1.1 to label the cycle $C_{n}$, we have to label the vertices $\left\{u_{1}, \ldots, u_{n}\right\}$ with the labels $\{5,6,7\}$ as follow:

If $n$ is odd:

$$
\begin{array}{ll}
f\left(u_{1}\right)=5 & \\
f\left(u_{2 i}\right)=6 & 1 \leq i \leq \frac{n-1}{2}, \\
f\left(u_{2 i+1}\right)=7 & 1 \leq i \leq \frac{n-1}{2} .
\end{array}
$$

If $n$ is even:

$$
\begin{array}{ll}
f\left(u_{2 i-1}\right)=6 & 1 \leq i \leq \frac{n}{2}, \\
f\left(u_{2 i}\right)=7 & 1 \leq i \leq \frac{n}{2} .
\end{array}
$$

Example : $\lambda(S F(7))=7$ and $\lambda(S F(8))=7$ as shown in the following Figure.
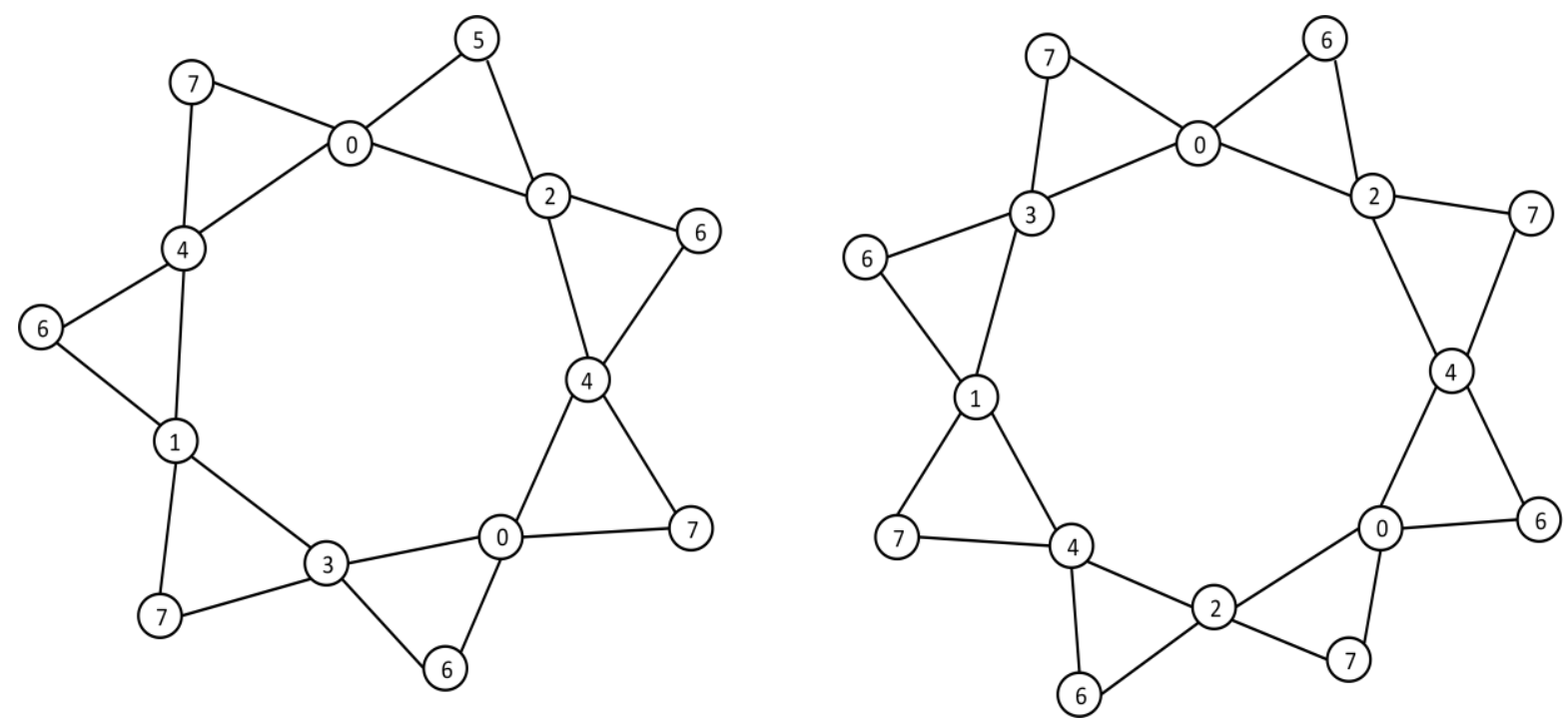

Figure 2.4: $\mathrm{L}(2,1)$ - labeling of $S F(7)$ and $S F(8)$ with $\lambda=7$

Theorem 2.2.5: The Cartesian Product $P_{n} \times C_{4}$ has the labeling number $\lambda\left(P_{n} \times C_{4}\right)=7$.

Proof: This graph has $|V|=4 n$ vertices and $|E|=4(2 n-1)$ edges. Let the set of vertices $V\left(P_{n} \times C_{4}\right)=$ $\left\{v_{i}^{j}: 1 \leq i \leq n, 1 \leq j \leq 4\right\}$. Using the following labeling function, we see that $\lambda\left(P_{n} \times C_{4}\right)=7$.

$$
f\left(v_{i}^{j}\right)=\left\{\begin{array}{ll}
0, & i \equiv 1(\bmod 4) \\
2, & i \equiv 2(\bmod 4) \\
5, & i \equiv 3(\bmod 4) \\
3, & i \equiv 0(\bmod 4)
\end{array}, \quad j \equiv 1(\bmod 4)\right.
$$


Military Technical College

Kobry Elkobbah,

Cairo, Egypt

May 29-31,2012

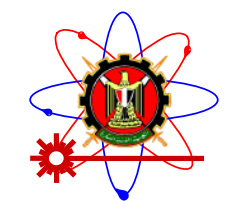

$6^{\text {th }}$ International Conference on Mathematics and

Engineering Physics (ICMEP-

6)

$$
\begin{aligned}
& f\left(v_{i}^{j}\right)=\left\{\begin{array}{ll}
6, & i \equiv 1(\bmod 4) \\
4, & i \equiv 2(\bmod 4) \\
7, & i \equiv 3(\bmod 4) \\
1, & i \equiv 0(\bmod 4)
\end{array}, \quad j \equiv 2(\bmod 4)\right. \\
& f\left(v_{i}^{j}\right)=\left\{\begin{array}{ll}
2, & i \equiv 1(\bmod 4) \\
0, & i \equiv 2(\bmod 4) \\
3, & i \equiv 3(\bmod 4) \\
5, & i \equiv 0(\bmod 4)
\end{array}, \quad j \equiv 3(\bmod 4)\right. \\
& f\left(v_{i}^{j}\right)=\left\{\begin{array}{ll}
4, & i \equiv 1(\bmod 4) \\
6, & i \equiv 2(\bmod 4) \\
1, & i \equiv 3(\bmod 4) \\
7, & i \equiv 0(\bmod 4)
\end{array}, \quad j \equiv 0(\bmod 4) .\right.
\end{aligned}
$$

Example: $\lambda\left(P_{6} \times C_{4}\right)=7$ as shown in the following Figure.

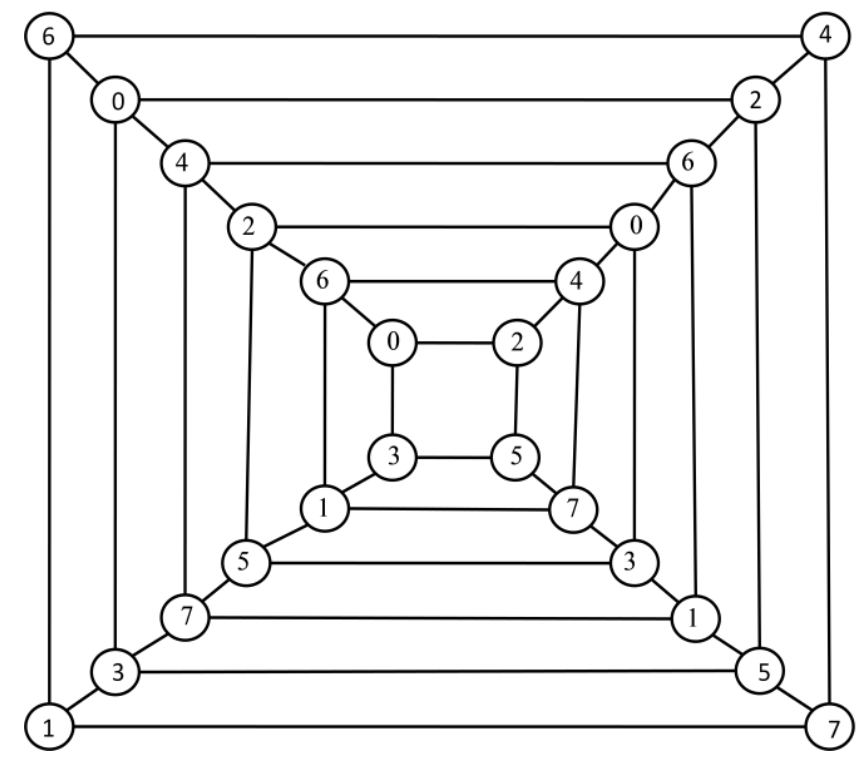

Figure 2.5: $\mathrm{L}(2,1)$ - labeling of graph $P_{6} \times C_{4}$ with $\lambda=7$

Theorem 2.2.6: The graph which is obtained from $C_{m}$ by attaching a pendent path $P_{n}$ to every vertex of $C_{m}$ has a labeling number $\lambda=5$.

Proof: This graph has nm vertices and $\mathrm{nm}$ edges. So, using the following labeling function, we see that the labeling number for this graph is $\lambda=5$.

We have three cases for this graph, the first case when $m \equiv 0(\bmod 3)$, the second case when $m \equiv$ $1(\bmod 3)$ and the third one when $m \equiv 2(\bmod 3)$

$\underline{1-m \equiv 0(\bmod 3):}$ 
Military Technical College

Kobry Elkobbah,

Cairo, Egypt

May 29-31,2012 $6^{\text {th }}$ International Conference on Mathematics and

Engineering Physics (ICMEP-

6)

In this case we will use the following labeling function,

$$
\begin{aligned}
& f\left(v_{i}^{j}\right)=\left\{\begin{array}{ll}
0, & j=1 \\
3, & j=2 \\
1, & j=3 \\
4, & j=1(\bmod 3) \\
j \neq 1 & j=2(\bmod 3) \\
0, & j \neq 2 \\
j=0(\bmod 3) \\
j \neq 3
\end{array}, \quad i \equiv 1(\bmod 3) .\right. \\
& f\left(v_{i}^{j}\right)= \begin{cases}2, & j \equiv 1(\bmod 3) \\
5, & j=2 \\
0, & j \equiv 0(\bmod 3), \quad i \equiv 2(\bmod 3) \\
4, & j \equiv 2(\bmod 3) \\
j \neq 2\end{cases} \\
& f\left(v_{i}^{j}\right)= \begin{cases}4, & j=1 \\
1, & j=2 \\
3, & j=3 \\
0, & j=1(\bmod 3) \\
j=1 \\
2, & j=2(\bmod 3) \\
j \neq 2 & j=0(\bmod 3) \\
4, & j \neq 3\end{cases}
\end{aligned}
$$

Example: The graph which is obtained from $C_{6}$ by attaching a pendent path $P_{6}$ to every vertex of $C_{6}$ is shown in the following Figure with a labeling number $\lambda=5$.

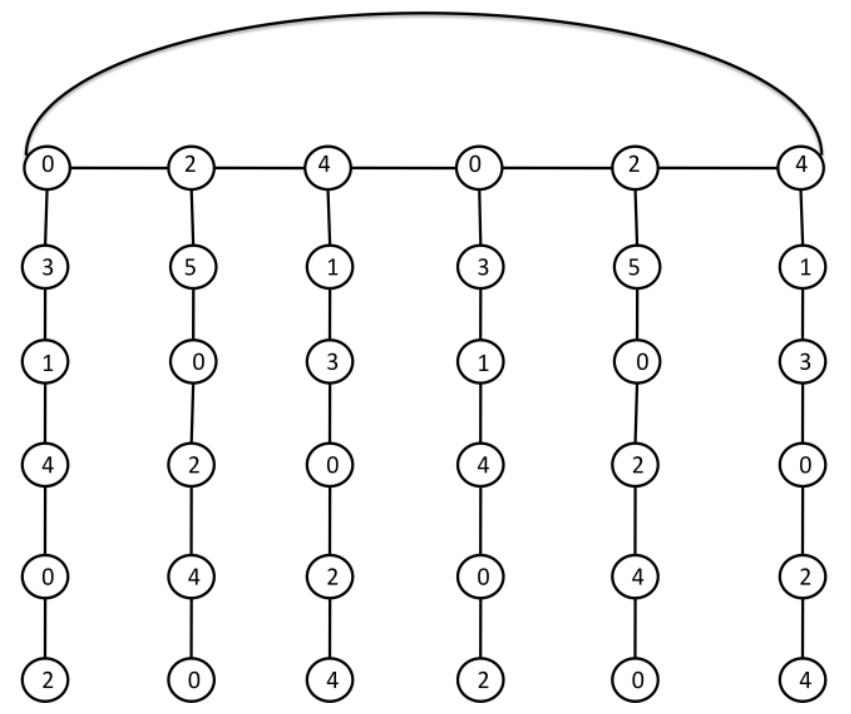

Figure 2.6: $\mathrm{L}(2,1)$ - labeling of graph which is obtained from $C_{6}$ by attaching a pendent path $P_{6}$ to every vertex of $C_{6}$ with $\lambda=5$

\section{$\underline{2-m \equiv 1(\bmod 3):}$}

In this case we will use the following labeling function, 
Military Technical College

Kobry Elkobbah,

Cairo, Egypt

May 29-31,2012



$6^{\text {th }}$ International Conference on Mathematics and

Engineering Physics (ICMEP-

6)

$$
\begin{aligned}
& f\left(v_{i}^{j}\right)=\left\{\begin{array}{ll}
4, & j=1 \\
1, & j=2 \\
3, & j=3 \\
0, & j=1(\bmod 3) \\
j \neq 1 & j=2(\bmod 3) \\
2, & j=2 \\
4, & j=0(\bmod 3) \\
j \neq 3 &
\end{array} \quad, i \equiv 0(\bmod 3),\right.
\end{aligned}
$$

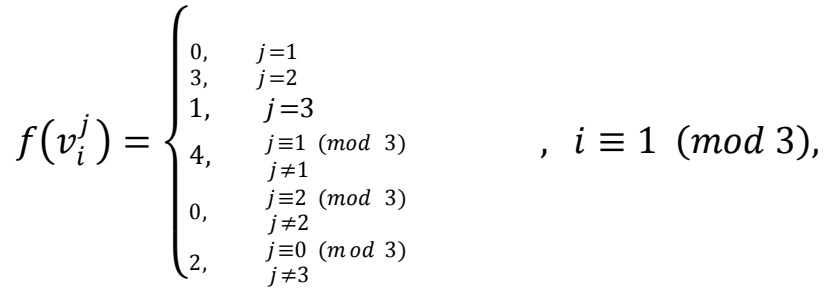

$$
\begin{aligned}
& f\left(v_{i}^{j}\right)= \begin{cases}2, & j \equiv 1(\bmod 3) \\
5, & j=2 \\
0, & j \equiv 0(\bmod 3) \\
4, & j \equiv 2(\bmod 3) \\
j \neq 2 & \end{cases}
\end{aligned}
$$

and the last four vertices are modified as follow:

$$
\begin{gathered}
f\left(v_{m-3}^{j}\right)= \begin{cases}0, & j \equiv 1(\bmod 3) \\
2, & j \equiv 2(\bmod 3), \\
4, & j \equiv 0(\bmod 3)\end{cases} \\
f\left(v_{m-2}^{j}\right)= \begin{cases}3, & j=1 \\
5, & j=2 \\
0, & j \equiv 0(\bmod 3) \\
2, & j \equiv 1(\bmod 3) \\
j \neq 1 & j \equiv 2(\bmod 3) \\
4, & j \neq 2\end{cases} \\
f\left(v_{m-1}^{j}\right)=\left\{\begin{array}{ll}
1, & j=1 \\
5, & j=2 \\
0, & j \equiv 0(\bmod 3) \\
2, & j \equiv 1(\bmod 3) \\
4, & j \equiv 2(\bmod 3)
\end{array},\right. \\
f\left(v_{m}^{j}\right)= \begin{cases}4, & j \equiv 1(\bmod 3) \\
2, & j \equiv 2(\bmod 3) . \\
0, & j \equiv 0(\bmod 3)\end{cases}
\end{gathered}
$$

Example: The graph which is obtained from $C_{7}$ by attaching a pendent path $P_{6}$ to every vertex of $C_{7}$ is shown in the following Figure with a labeling number $\lambda=5$. 
Military Technical College

Kobry Elkobbah,

Cairo, Egypt

May 29-31,2012
$6^{\text {th }}$ International Conference on Mathematics and

Engineering Physics (ICMEP-

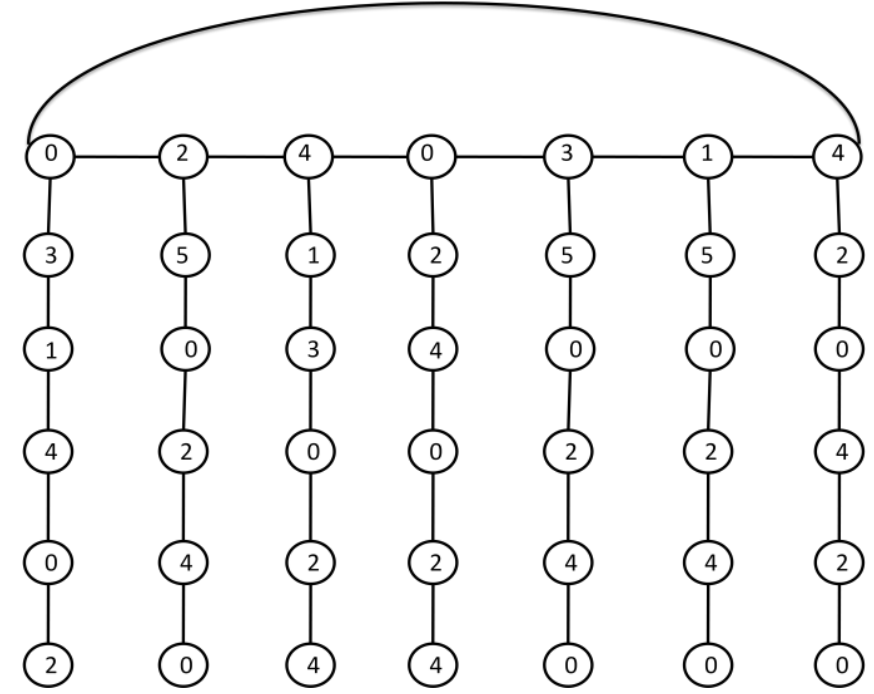

Figure 2.7: $\mathrm{L}(2,1)$ - labeling of graph which is obtained from $C_{7}$ by attaching a pendent path $P_{6}$ to every vertex of $C_{7}$ with $\lambda=5$

\section{$\underline{3-m \equiv 2(\bmod 3):}$}

In this case we will use the following labeling function,

$$
\begin{aligned}
& f\left(v_{1}^{j}\right)= \begin{cases}0, & j \equiv 1(\bmod 3) \\
4, & j \equiv 2(\bmod 3), \\
2, & j \equiv 0(\bmod 3)\end{cases} \\
& f\left(v_{i}^{j}\right)= \begin{cases}2, & j \equiv 1(\bmod 3) \\
5, & j=2 \\
0, & j \equiv 0(\bmod 3), \quad i \equiv 2(\bmod 3), \\
4, & j=2(\bmod 3) \\
j \neq 2\end{cases}
\end{aligned}
$$

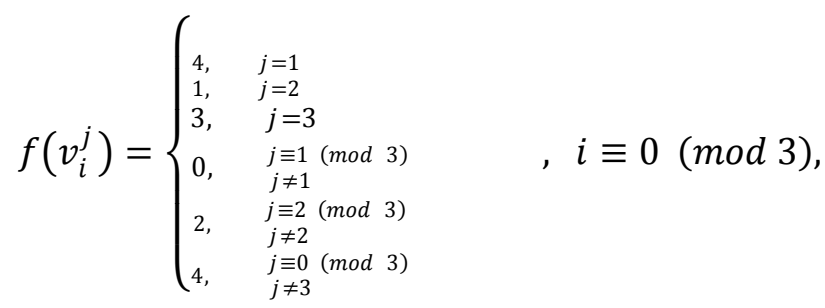

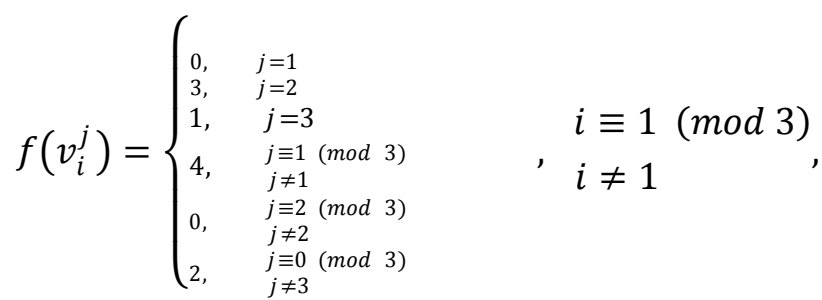

and the last three vertices are modified as follow: 
Military Technical College

Kobry Elkobbah,

Cairo, Egypt

May 29-31,2012

\section{$6^{\text {th }}$ International Conference on Mathematics and}

Engineering Physics (ICMEP-

6)

$$
\begin{gathered}
f\left(v_{m-2}^{j}\right)= \begin{cases}4, & j \equiv 1(\bmod 3) \\
0, & j \equiv 2(\bmod 3), \\
2, & j \equiv 0(\bmod 3)\end{cases} \\
f\left(v_{m-1}^{j}\right)=\left\{\begin{array}{ll}
1, & j=1 \\
5, & j=2 \\
0, & j \equiv 0(\bmod 3) \\
2, & j \equiv 1(\bmod 3) \\
4, & j \equiv 2(\bmod 3)
\end{array},\right. \\
f\left(v_{m}^{j}\right)= \begin{cases}3, & j=1 \\
0, & j \equiv 2(\bmod 3) \\
2, & j \equiv 0(\bmod 3) \\
5, & j \equiv 1(\bmod 3) \\
j \neq 1\end{cases}
\end{gathered}
$$

Example: The graph which is obtained from $C_{8}$ by attaching a pendent path $P_{6}$ to every vertex of $C_{8}$ is shown in the following Figure with a labeling number $\lambda=5$.

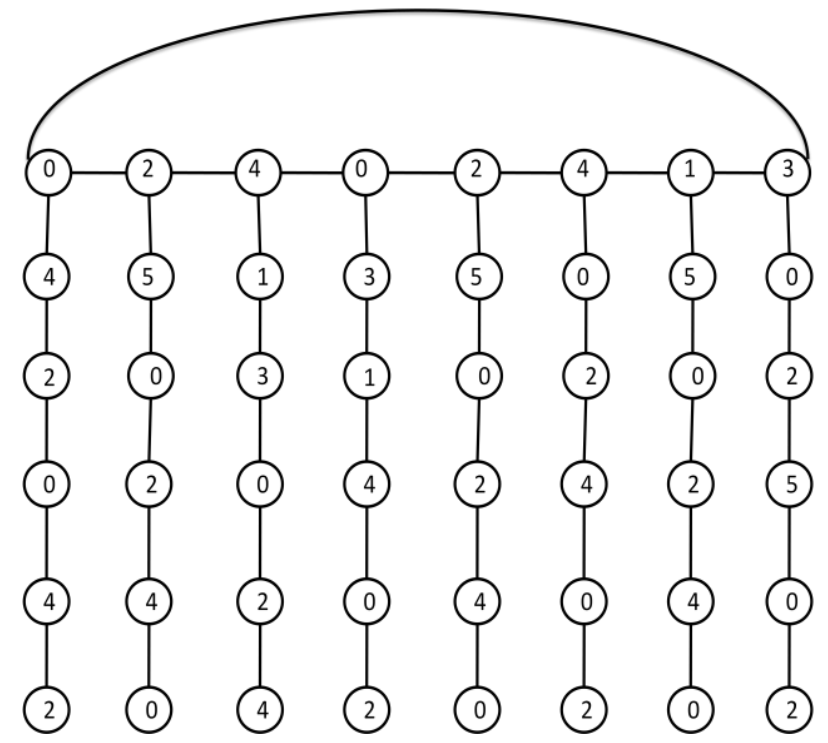

Figure 2.8: $\mathrm{L}(2,1)$ - labeling of graph which is obtained from $C_{8}$ by attaching a pendent path $P_{6}$ to every vertex of $C_{8}$ with $\lambda=5$ 
Military Technical College

Kobry Elkobbah,

Cairo, Egypt

May 29-31,2012

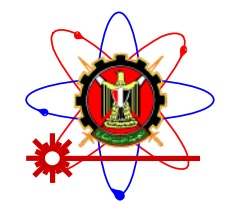

$6^{\text {th }}$ International Conference on Mathematics and

Engineering Physics (ICMEP-

6)

\section{Prime Cordial labeling}

\subsection{Back ground}

Sundaram, Ponraj, and Somasundaram [3] have introduced the notion of prime cordial labelings. A prime cordial labeling of a graph $G$ with vertex set $V$ is a bijection $f$ from $V$ to $\{1,2, \ldots,|V|\}$ such that if each edge $u v$ is assigned the label 1 if $\operatorname{gcd}(f(u), f(v))=1$ and 0 if $\operatorname{gcd}(f(u), f(v))>1$, then the number of edges labeled with 0 and the number of edges labeled with 1 differ by at most 1. In [3] Sundaram, Ponraj, and Somasundram prove the following graphs are prime cordial: $C_{n}$ if and only if $n \geq 6$; $P_{n}$ if and only if $n \neq 3$ or $5 ; K_{1, n}$ (n odd); the graph obtained by subdividing each edge of $K_{1, n}$ if and only if $n \geq 3$; bistars; dragons; crowns; triangular snakes if and only if the snake has at least three triangles; ladders; $K_{1, n}$ if $n$ is even and there exists a prime $p$ such that $2 p<n+1<3 p ; K_{2, n}$ if $n$ is even and if there exists a prime $p$ such that $3 p<n+2<4 p$; and $K_{3, n}$ if $n$ is odd and if there exists a prime $p$ such that $5 p<n+3<6 p$. They also prove that if $G$ is a prime cordial graph of even size, then the graph obtained by identifying the central vertex of $K_{1, n}$ with the vertex of $G$ labeled with 2 is prime cordial, and if $G$ is a prime cordial graph of odd size, then the graph obtained by identifying the central vertex of $K_{1,2 n}$ with the vertex of $G$ labeled with 2 is prime cordial. They further prove that $K_{m, n}$ is not prime cordial for a number of special cases of $m$ and $n$. Sundaram and Somasundaram and Youssef observed that for $n \geq 3, K_{n}$ is not prime cordial provided that the inequality $\varphi(2)+\varphi(3)+\cdots+\varphi(\mathrm{n})>n(n-1) / 4+1$ is valid for $n \geq 3$. This inequality was proved by Yufei Zhao.

\subsection{New results}

Theorem 3.2.1: A necessary condition for a graph $G$ of order $n$ to be a prime cordial graph, is that its number of edges $|E(G)| \leq m+1$, where

$$
\begin{array}{r}
m=\sum_{\substack{i, j=1 \\
i \neq j}}^{n} a\left(v_{i}, v_{j}\right): a\left(v_{i}, v_{j}\right)=1 \text { iff } \operatorname{gcd}\left(f\left(v_{i}\right), f\left(v_{j}\right)\right)>1, \\
\text { and } a\left(v_{i}, v_{j}\right)=0 \text { iff } \operatorname{gcd}\left(f\left(v_{i}\right), f\left(v_{j}\right)\right)=1 .
\end{array}
$$

Proof: we count the all edges could be labeled 0; that is counting edges whose adjacent vertices labels' are not relatively prime.

By using next algorithm, we count these edges and make a table representing the upper bound $m+1$ for the number of vertices $2 \leq n \leq 600$ as shown in table 1 . 
Military Technical College

Kobry Elkobbah,

Cairo, Egypt

May 29-31,2012

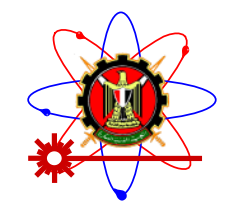

$6^{\text {th }}$ International Conference on Mathematics and

Engineering Physics (ICMEP-

6)

\section{Algorithm 3.2.2:}

We make an algorithm to make a table for the upper bound for the number of edges of any graph with the number of vertices equal to $n$ to be prime cordial graph.

INPUT The size of the table according to the number of vertices.

OUTPUT The upper bound for the number of edges corresponding to the number of vertices $n$.

Step 1: Set p; (size of the table)

$\mathrm{x}$; (multiples of the prime divisors)

$\mathrm{m}$; (used to count the number of labels that are not relatively prime with each other)

a; (array to store the prime divisors of the composite divisors)

$\mathrm{b}$; (array to store the multiples of the prime divisors of the composite divisors)

Step 2: Enter the size of the table in $\mathrm{p}$;

Step 3: FOR index $\mathrm{i}=2: \mathrm{p}$

Step 4: Initialize count $=0$;

Step 5: FOR index $\mathrm{j}=2: \mathrm{i}$

Step 6: Check if $\mathrm{j}$ is prime or not using a SUBFUNCTION prime(j);

Step 7: If $\mathrm{j}$ is prime

Step 8: Get the multiples of $\mathrm{j}$ and store in $\mathrm{x}$ and count them;

Step 9: Store the number of multiples in $\mathrm{m}$;

Step 10: If $\mathrm{j}$ is not prime

Step 11: Get the prime divisors of $\mathrm{j}$ without repetitions and store in array a;

Step 12: Get the multiples for each prime divisor stored in array a and store in array b without repetition;

Step 13: Count the labels stored in array $\mathrm{b}$ and store in $\mathrm{m}$;

Step 14: count $=$ count $+\mathrm{m}$;

Step 15: OUTPUT (i and $\mathrm{m}+1$ );

Step 13: STOP;

We implement this algorithm using $\mathrm{C}^{++}$programming language.

Result 3.2.3: In table 2 we present the number of edges of the graphs $G_{i}$ (where $G_{i}$ is a regular graph with degree $n-i$ ) compared with the upper bound calculated in table 1 and deduce that $G_{i}, i=3,4 \ldots, 10$ are not prime cordial graphs for the underlined bold numbers. 
Military Technical College

Kobry Elkobbah,

Cairo, Egypt

May 29-31,2012

\section{$6^{\text {th }}$ International Conference on Mathematics and}

Engineering Physics (ICMEP-

6)

Result 3.2.4: In table 3 we present the number of edges of the graphs $C_{n}^{i}$ (where $E_{n}^{i}=\left|E\left(C_{n}^{i}\right)\right|$ ) compared with the upper bound calculated in table 1 and deduce that $C_{n}^{i}, i=2,3,4 \ldots, 12$ are not prime cordial graphs for the underlined bold numbers.

\section{References}

[1] A.A. Bertossi and M. Cristina Pinotti, Wireless Ad Hok Networking, Taylor \& Francis group, LLC, 2007.

[2] F. Harary, Graph Theory (Addison-Wesley, Reading, MA 1969).

[3] M. Sundaram, R. Ponraj, and S. Somasundram, Prime cordial labeling of graphs, J. Indian Acad. Math., 27 (2005) 373-390.

[4] Z. Shao, Roger K. Yeh, Kin Keung Poon, Wai Chee Shiu, The L(2, 1)-labeling of K1,n-free graphs and its applications, Applied Mathematics Letters 21 (2008) 1188-1193.

Table 1: Upper bound for the number of edges of a graph with $\mathrm{n}$ vertices to be prime cordial.

\begin{tabular}{|c|c||c|c||c|c||c|c||c|c||}
\hline$n$ & $m+1$ & $n$ & $m+1$ & $n$ & $m+1$ & $n$ & $m+1$ & $n$ & $m+1$ \\
\hline \hline 2 & 1 & 59 & 1253 & 116 & 5087 & 173 & 11371 & 230 & 20365 \\
\hline 3 & 1 & 60 & 1339 & 117 & 5175 & 174 & 11605 & 231 & 20585 \\
\hline 4 & 3 & 61 & 1339 & 118 & 5293 & 175 & 11713 & 232 & 20823 \\
\hline 5 & 3 & 62 & 1401 & 119 & 5337 & 176 & 11903 & 233 & 20823 \\
\hline 6 & 9 & 63 & 1453 & 120 & 5511 & 177 & 12023 & 234 & 21145 \\
\hline 7 & 9 & 64 & 1515 & 121 & 5531 & 178 & 12201 & 235 & 21245 \\
\hline 8 & 15 & 65 & 1547 & 122 & 5653 & 179 & 12201 & 236 & 21483 \\
\hline 9 & 19 & 66 & 1637 & 123 & 5737 & 180 & 12463 & 237 & 21643 \\
\hline 10 & 29 & 67 & 1637 & 124 & 5863 & 181 & 12463 & 238 & 21925 \\
\hline 11 & 29 & 68 & 1707 & 125 & 5911 & 182 & 12681 & 239 & 21925 \\
\hline 12 & 43 & 69 & 1755 & 126 & 6089 & 183 & 12805 & 240 & 22275 \\
\hline 13 & 43 & 70 & 1845 & 127 & 6089 & 184 & 12995 & 241 & 22275 \\
\hline 14 & 57 & 71 & 1845 & 128 & 6215 & 185 & 13075 & 242 & 22537 \\
\hline 15 & 69 & 72 & 1939 & 129 & 6303 & 186 & 13325 & 243 & 22697 \\
\hline
\end{tabular}


Military Technical College

Kobry Elkobbah,

Cairo, Egypt

May 29-31,2012

\section{$6^{\text {th }}$ International Conference on Mathematics and \\ Engineering Physics (ICMEP-}

6)

\begin{tabular}{|c|c|c|c|c|c|c|c|c|c|}
\hline 16 & 83 & 73 & 1939 & 130 & 6465 & 187 & 13377 & 244 & 22943 \\
\hline 17 & 83 & 74 & 2013 & 131 & 6465 & 188 & 13567 & 245 & 23095 \\
\hline 18 & 105 & 75 & 2081 & 132 & 6647 & 189 & 13727 & 246 & 23425 \\
\hline 19 & 105 & 76 & 2159 & 133 & 6695 & 190 & 13961 & 247 & 23485 \\
\hline 20 & 127 & 77 & 2191 & 134 & 6829 & 191 & 13961 & 248 & 23739 \\
\hline 21 & 143 & 78 & 2297 & 135 & 6953 & 192 & 14215 & 249 & 23907 \\
\hline 22 & 165 & 79 & 2297 & 136 & 7095 & 193 & 14215 & 250 & 24205 \\
\hline 23 & 165 & 80 & 2391 & 137 & 7095 & 194 & 14409 & 251 & 24205 \\
\hline 24 & 195 & 81 & 2443 & 138 & 7281 & 195 & 14605 & 252 & 24563 \\
\hline 25 & 203 & 82 & 2525 & 139 & 7281 & 196 & 14827 & 253 & 24627 \\
\hline 26 & 229 & 83 & 2525 & 140 & 7463 & 197 & 14827 & 254 & 24881 \\
\hline 27 & 245 & 84 & 2643 & 141 & 7559 & 198 & 15101 & 255 & 25133 \\
\hline 28 & 275 & 85 & 2683 & 142 & 7701 & 199 & 15101 & 256 & 25387 \\
\hline 29 & 275 & 86 & 2769 & 143 & 7745 & 200 & 15339 & 257 & 25387 \\
\hline 30 & 317 & 87 & 2829 & 144 & 7935 & 201 & 15475 & 258 & 25733 \\
\hline 31 & 317 & 88 & 2923 & 145 & 7999 & 202 & 15677 & 259 & 25817 \\
\hline 32 & 347 & 89 & 2923 & 146 & 8145 & 203 & 15745 & 260 & 26143 \\
\hline 33 & 371 & 90 & 3053 & 147 & 8269 & 204 & 16023 & 261 & 26327 \\
\hline 34 & 405 & 91 & 3089 & 148 & 8419 & 205 & 16111 & 262 & 26589 \\
\hline 35 & 425 & 92 & 3183 & 149 & 8419 & 206 & 16317 & 263 & 26589 \\
\hline 36 & 471 & 93 & 3247 & 150 & 8637 & 207 & 16465 & 264 & 26955 \\
\hline 37 & 471 & 94 & 3341 & 151 & 8637 & 208 & 16687 & 265 & 27067 \\
\hline 38 & 509 & 95 & 3385 & 152 & 8795 & 209 & 16743 & 266 & 27381 \\
\hline 39 & 537 & 96 & 3511 & 153 & 8907 & 210 & 17065 & 267 & 27561 \\
\hline 40 & 583 & 97 & 3511 & 154 & 9093 & 211 & 17065 & 268 & 27831 \\
\hline 41 & 583 & 98 & 3621 & 155 & 9161 & 212 & 17279 & 269 & 27831 \\
\hline 42 & 641 & 99 & 3697 & 156 & 9375 & 213 & 17423 & 270 & 28225 \\
\hline 43 & 641 & 100 & 3815 & 157 & 9375 & 214 & 17637 & 271 & 28225 \\
\hline 44 & 687 & 101 & 3815 & 158 & 9533 & 215 & 17729 & 272 & 28511 \\
\hline 45 & 727 & 102 & 3953 & 159 & 9641 & 216 & 18015 & 273 & 28767 \\
\hline 46 & 773 & 103 & 3953 & 160 & 9831 & 217 & 18087 & 274 & 29041 \\
\hline 47 & 773 & 104 & 4063 & 161 & 9887 & 218 & 18305 & 275 & 29189 \\
\hline 48 & 835 & 105 & 4175 & 162 & 10101 & 219 & 18453 & 276 & 29563 \\
\hline 49 & 847 & 106 & 4281 & 163 & 10101 & 220 & 18731 & 277 & 29563 \\
\hline 50 & 905 & 107 & 4281 & 164 & 10267 & 221 & 18787 & 278 & 29841 \\
\hline 51 & 941 & 108 & 4423 & 165 & 10435 & 222 & 19085 & 279 & 30037 \\
\hline 52 & 995 & 109 & 4423 & 166 & 10601 & 223 & 19085 & 280 & 30403 \\
\hline 53 & 995 & 110 & 4561 & 167 & 10601 & 224 & 19339 & 281 & 30403 \\
\hline 54 & 1065 & 111 & 4637 & 168 & 10839 & 225 & 19547 & 282 & 30781 \\
\hline 55 & 1093 & 112 & 4763 & 169 & 10863 & 226 & 19773 & 283 & 30781 \\
\hline 56 & 1155 & 113 & 4763 & 170 & 11073 & 227 & 19773 & 284 & 31067 \\
\hline 57 & 1195 & 114 & 4917 & 171 & 11197 & 228 & 20083 & 285 & 31347 \\
\hline 58 & 1253 & 115 & 4969 & 172 & 11371 & 229 & 20083 & 286 & 31677 \\
\hline
\end{tabular}

\begin{tabular}{|c|c||c|c||c|c||c|c||c|c||c|c||}
\hline$n$ & $m+1$ & $n$ & $m+1$ & $n$ & $m+1$ & $n$ & $m+1$ & $n$ & $m+1$ & $n$ & $m+1$ \\
\hline \hline 287 & 31769 & 345 & 46219 & 402 & 62785 & 459 & 81849 & 516 & 103727 & 573 & 127711 \\
\hline 288 & 32151 & 346 & 46565 & 403 & 62869 & 460 & 82415 & 517 & 103839 & 574 & 128377 \\
\hline 289 & 32183 & 347 & 46565 & 404 & 63275 & 461 & 82415 & 518 & 104441 & 575 & 128645 \\
\hline 290 & 32537 & 348 & 47035 & 405 & 63651 & 462 & 83097 & 519 & 104789 & 576 & 129411 \\
\hline 291 & 32733 & 349 & 47035 & 406 & 64125 & 463 & 83097 & 520 & 105443 & 577 & 129411 \\
\hline
\end{tabular}


Military Technical College

Kobry Elkobbah,

Cairo, Egypt

May 29-31,2012

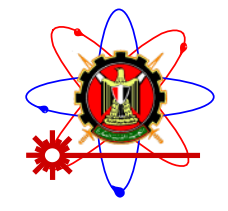

$6^{\text {th }}$ International Conference on Mathematics and

Engineering Physics (ICMEP-

6)

\begin{tabular}{|c|c|c|c|c|c|c|c|c|c|c|c|}
\hline 292 & 33027 & 350 & 47493 & 407 & 64217 & 464 & 83575 & 521 & 105443 & 578 & 130021 \\
\hline 293 & 33027 & 351 & 47761 & 408 & 64775 & 465 & 84023 & 522 & 106149 & 579 & 130409 \\
\hline 294 & 33445 & 352 & 48143 & 409 & 64775 & 466 & 84489 & 523 & 106149 & 580 & 131119 \\
\hline 295 & 33569 & 353 & 48143 & 410 & 65273 & 467 & 84489 & 524 & 106675 & 581 & 131295 \\
\hline 296 & 33871 & 354 & 48617 & 411 & 65549 & 468 & 85135 & 525 & 107243 & 582 & 132073 \\
\hline 297 & 34103 & 355 & 48765 & 412 & 65963 & 469 & 85279 & 526 & 107769 & 583 & 132197 \\
\hline 298 & 34401 & 356 & 49123 & 413 & 66091 & 470 & 85849 & 527 & 107861 & 584 & 132787 \\
\hline 299 & 34469 & 357 & 49451 & 414 & 66653 & 471 & 86165 & 528 & 108595 & 585 & 133379 \\
\hline 300 & 34907 & 358 & 49809 & 415 & 66825 & 472 & 86643 & 529 & 108639 & 586 & 133965 \\
\hline 301 & 35003 & 359 & 49809 & 416 & 67271 & 473 & 86747 & 530 & 109281 & 587 & 133965 \\
\hline 302 & 35305 & 360 & 50335 & 417 & 67551 & 474 & 87381 & 531 & 109645 & 588 & 134803 \\
\hline 303 & 35509 & 361 & 50371 & 418 & 68025 & 475 & 87609 & 532 & 110275 & 589 & 134899 \\
\hline 304 & 35827 & 362 & 50733 & 419 & 68025 & 476 & 88175 & 533 & 110379 & 590 & 135613 \\
\hline 305 & 35955 & 363 & 51017 & 420 & 68671 & 477 & 88503 & 534 & 111093 & 591 & 136009 \\
\hline 306 & 36373 & 364 & 51455 & 421 & 68671 & 478 & 88981 & 535 & 111313 & 592 & 136615 \\
\hline 307 & 36373 & 365 & 51607 & 422 & 69093 & 479 & 88981 & 536 & 111855 & 593 & 136615 \\
\hline 308 & 36747 & 366 & 52097 & 423 & 69385 & 480 & 89683 & 537 & 112215 & 594 & 137441 \\
\hline 309 & 36955 & 367 & 52097 & 424 & 69815 & 481 & 89779 & 538 & 112753 & 595 & 137861 \\
\hline 310 & 37333 & 368 & 52479 & 425 & 70023 & 482 & 90261 & 539 & 112989 & 596 & 138459 \\
\hline 311 & 37333 & 369 & 52735 & 426 & 70593 & 483 & 90697 & 540 & 113779 & 597 & 138859 \\
\hline 312 & 37763 & 370 & 53185 & 427 & 70725 & 484 & 91223 & 541 & 113779 & 598 & 139525 \\
\hline 313 & 37763 & 371 & 53301 & 428 & 71155 & 485 & 91423 & 542 & 114321 & 599 & 139525 \\
\hline 314 & 38077 & 372 & 53803 & 429 & 71531 & 486 & 92069 & 543 & 114685 & 600 & 140403 \\
\hline 315 & 38417 & 373 & 53803 & 430 & 72053 & 487 & 92069 & 544 & 115259 & & \\
\hline 316 & 38735 & 374 & 54229 & 431 & 72053 & 488 & 92563 & 545 & 115483 & & \\
\hline 317 & 38735 & 375 & 54577 & 432 & 72627 & 489 & 92891 & 546 & 116285 & & \\
\hline 318 & 39161 & 376 & 54959 & 433 & 72627 & 490 & 93533 & 547 & 116285 & & \\
\hline 319 & 39237 & 377 & 55039 & 434 & 73133 & 491 & 93533 & 548 & 116835 & & \\
\hline 320 & 39619 & 378 & 55577 & 435 & 73553 & 492 & 94195 & 549 & 117211 & & \\
\hline 321 & 39835 & 379 & 55577 & 436 & 73991 & 493 & 94283 & 550 & 117909 & & \\
\hline 322 & 40213 & 380 & 56047 & 437 & 74071 & 494 & 94837 & 551 & 118001 & & \\
\hline 323 & 40281 & 381 & 56303 & 438 & 74657 & 495 & 95345 & 552 & 118751 & & \\
\hline 324 & 40711 & 382 & 56685 & 439 & 74657 & 496 & 95855 & 553 & 118919 & & \\
\hline 325 & 40879 & 383 & 56685 & 440 & 75215 & 497 & 96007 & 554 & 119473 & & \\
\hline 326 & 41205 & 384 & 57195 & 441 & 75591 & 498 & 96673 & 555 & 120005 & & \\
\hline 327 & 41425 & 385 & 57483 & 442 & 76089 & 499 & 96673 & 556 & 120563 & & \\
\hline 328 & 41759 & 386 & 57869 & 443 & 76089 & 500 & 97271 & 557 & 120563 & & \\
\hline 329 & 41863 & 387 & 58137 & 444 & 76687 & 501 & 97607 & 558 & 121317 & & \\
\hline 330 & 42361 & 388 & 58527 & 445 & 76871 & 502 & 98109 & 559 & 121425 & & \\
\hline 331 & 42361 & 389 & 58527 & 446 & 77317 & 503 & 98109 & 560 & 122159 & & \\
\hline 332 & 42695 & 390 & 59113 & 447 & 77617 & 504 & 98827 & 561 & 122639 & & \\
\hline 333 & 42927 & 391 & 59189 & 448 & 78127 & 505 & 99035 & 562 & 123201 & & \\
\hline 334 & 43261 & 392 & 59635 & 449 & 78127 & 506 & 99605 & 563 & 123201 & & \\
\hline 335 & 43401 & 393 & 59899 & 450 & 78785 & 507 & 99993 & 564 & 123959 & & \\
\hline 336 & 43879 & 394 & 60293 & 451 & 78885 & 508 & 100503 & 565 & 124191 & & \\
\hline 337 & 43879 & 395 & 60457 & 452 & 79339 & 509 & 100503 & 566 & 124757 & & \\
\hline 339 & 44469 & 396 & 61007 & 453 & 79643 & 510 & 101265 & 567 & 125241 & & \\
\hline 340 & 44891 & 397 & 61007 & 454 & 80097 & 511 & 101421 & 568 & 125815 & & \\
\hline 341 & 44971 & 398 & 61405 & 455 & 80429 & 512 & 101931 & 569 & 125815 & & \\
\hline 342 & 45437 & 399 & 61769 & 456 & 81051 & 513 & 102307 & 570 & 126665 & & \\
\hline 343 & 45533 & 400 & 62247 & 457 & 81051 & 514 & 102821 & 571 & 126665 & & \\
\hline 344 & 45883 & 401 & 62247 & 458 & 81509 & 515 & 103033 & 572 & 127327 & & \\
\hline
\end{tabular}

Table 2: A table giving the number of edges of $G_{i}\left|E\left(G_{i}\right)\right|$ compared with $m+1$. 
Military Technical College

Kobry Elkobbah,

Cairo, Egypt

May 29-31,2012 $6^{\text {th }}$ International Conference on Mathematics and

Engineering Physics (ICMEP-

6)

\begin{tabular}{|c|c|c|c|c|c|c|c|c|c|}
\hline 1 & $n$ & $\left|E\left(G_{3}\right)\right|$ & $\left|E\left(G_{4}\right)\right|$ & $\left|E\left(G_{5}\right)\right|$ & $\left|E\left(G_{6}\right)\right|$ & $\left|E\left(G_{7}\right)\right|$ & $\left|E\left(G_{8}\right)\right|$ & $\left|E\left(G_{9}\right)\right|$ & $\left|E\left(G_{10}\right)\right|$ \\
\hline 2 & 1 & & & & & & & & \\
\hline 3 & 1 & & & & & & & & \\
\hline 4 & 3 & 2 & & & & & & & \\
\hline 5 & 9 & 5 & & & & & & & \\
\hline 6 & 9 & 9 & 6 & 3 & & & & & \\
\hline 7 & 9 & $\underline{14}$ & & 7 & & & & & \\
\hline 8 & 15 & $\underline{20}$ & $\underline{16}$ & 12 & 8 & 4 & & & \\
\hline 9 & 19 & $\underline{27}$ & & 18 & & 9 & & & \\
\hline 10 & 29 & $\underline{35}$ & $\underline{30}$ & 25 & 20 & 15 & 10 & 5 & \\
\hline 11 & 29 & $\underline{44}$ & & $\underline{33}$ & & 22 & & 11 & \\
\hline 12 & 43 & $\underline{54}$ & $\underline{48}$ & 42 & 36 & 30 & 24 & 18 & 12 \\
\hline 13 & 43 & $\underline{65}$ & & $\underline{52}$ & & 39 & & 26 & \\
\hline 14 & 57 & $\underline{77}$ & $\underline{70}$ & $\underline{63}$ & 56 & 49 & 42 & 35 & 28 \\
\hline 15 & 69 & $\underline{90}$ & & $\underline{75}$ & & 60 & & 45 & \\
\hline 16 & 83 & $\underline{104}$ & $\underline{96}$ & 88 & 80 & 72 & 64 & 56 & 48 \\
\hline 17 & 83 & $\underline{119}$ & & $\underline{102}$ & & $\underline{85}$ & & 68 & \\
\hline 18 & 105 & $\underline{135}$ & $\underline{126}$ & $\underline{117}$ & $\underline{108}$ & 99 & 90 & 81 & 72 \\
\hline 19 & 105 & $\underline{152}$ & & $\underline{133}$ & & $\underline{114}$ & & 95 & \\
\hline 20 & 127 & $\underline{170}$ & $\underline{160}$ & $\underline{150}$ & $\underline{140}$ & $\underline{130}$ & 120 & 110 & 100 \\
\hline 21 & 143 & $\underline{189}$ & & $\underline{168}$ & & $\underline{147}$ & & 126 & \\
\hline 22 & 165 & $\underline{209}$ & $\underline{198}$ & $\underline{187}$ & $\underline{176}$ & 165 & 154 & 143 & 132 \\
\hline 23 & 165 & $\underline{230}$ & & $\underline{207}$ & & $\underline{184}$ & & 161 & \\
\hline 24 & 195 & $\underline{252}$ & $\underline{240}$ & $\underline{228}$ & $\underline{216}$ & $\underline{204}$ & 192 & 180 & 168 \\
\hline 25 & 203 & $\underline{275}$ & & $\underline{250}$ & & $\underline{225}$ & & 200 & \\
\hline 26 & 229 & $\underline{299}$ & $\underline{286}$ & $\underline{273}$ & $\underline{260}$ & 247 & $\underline{234}$ & 221 & 208 \\
\hline 27 & 245 & $\underline{324}$ & & $\underline{297}$ & & $\underline{270}$ & & 243 & \\
\hline 28 & 275 & $\underline{350}$ & $\underline{336}$ & $\underline{322}$ & $\underline{308}$ & $\underline{294}$ & $\underline{280}$ & 266 & 252 \\
\hline 29 & 275 & 377 & & $\underline{348}$ & & $\underline{319}$ & & $\underline{290}$ & \\
\hline 30 & 317 & $\underline{405}$ & $\underline{390}$ & $\underline{375}$ & $\underline{360}$ & $\underline{345}$ & $\underline{330}$ & 315 & 300 \\
\hline 31 & 317 & $\underline{434}$ & & $\underline{403}$ & & $\underline{372}$ & & 341 & \\
\hline 32 & 347 & $\underline{464}$ & $\underline{448}$ & $\underline{432}$ & $\underline{416}$ & $\underline{400}$ & $\underline{384}$ & $\underline{368}$ & 352 \\
\hline 33 & 371 & $\underline{495}$ & & $\underline{462}$ & & $\underline{429}$ & & $\underline{396}$ & \\
\hline 34 & 405 & $\underline{527}$ & $\underline{510}$ & $\underline{493}$ & $\underline{476}$ & $\underline{459}$ & $\underline{442}$ & $\underline{425}$ & $\underline{408}$ \\
\hline 35 & 425 & $\underline{560}$ & & $\underline{525}$ & & $\underline{490}$ & & $\underline{455}$ & \\
\hline 36 & 471 & 594 & $\underline{576}$ & $\underline{558}$ & $\underline{540}$ & $\underline{522}$ & $\underline{504}$ & 486 & 468 \\
\hline 37 & 471 & $\underline{629}$ & & $\underline{592}$ & & $\underline{555}$ & & $\underline{518}$ & \\
\hline 38 & 509 & $\underline{665}$ & $\underline{646}$ & $\underline{627}$ & $\underline{608}$ & $\underline{589}$ & $\underline{570}$ & $\underline{551}$ & $\underline{532}$ \\
\hline 39 & 537 & $\underline{702}$ & & $\underline{663}$ & & 624 & & $\underline{585}$ & \\
\hline 40 & 583 & $\underline{740}$ & $\underline{720}$ & $\underline{700}$ & $\underline{680}$ & $\underline{660}$ & $\underline{640}$ & $\underline{620}$ & 600 \\
\hline 41 & 583 & $\underline{779}$ & & $\underline{738}$ & & $\underline{697}$ & & $\underline{656}$ & \\
\hline
\end{tabular}


Military Technical College

Kobry Elkobbah,

Cairo, Egypt

May 29-31,2012 $6^{\text {th }}$ International Conference on Mathematics and

Engineering Physics (ICMEP-

6)

Table 3: A table giving the number of edges $\left(\left|E\left(C_{n}^{i}\right)\right|\right)$ compared with $m+1$.

\begin{tabular}{|c|c|c|c|c|c|c|c|c|c|c|c|c|}
\hline$n$ & $m+1$ & $E_{n}^{2}$ & $E_{n}^{3}$ & $E_{n}^{4}$ & $E_{n}^{5}$ & $E_{n}^{6}$ & $E_{n}^{7}$ & $E_{n}^{8}$ & $E_{n}^{9}$ & $E_{n}^{10}$ & $E_{n}^{11}$ & $E_{n}^{12}$ \\
\hline 2 & 1 & & & & & & & & & & & \\
\hline 3 & 1 & & & & & & & & & & & \\
\hline 4 & 3 & $\underline{6}$ & & & & & & & & & & \\
\hline 5 & 9 & $\underline{10}$ & $\underline{10}$ & & & & & & & & & \\
\hline 6 & 9 & $\underline{12}$ & $\underline{15}$ & & & & & & & & & \\
\hline 7 & 9 & $\underline{14}$ & $\underline{21}$ & & & & & & & & & \\
\hline 8 & 15 & $\underline{16}$ & $\underline{24}$ & $\underline{28}$ & & & & & & & & \\
\hline 9 & 19 & 18 & $\underline{27}$ & $\underline{36}$ & & & & & & & & \\
\hline 10 & 29 & 20 & $\underline{30}$ & $\underline{40}$ & $\underline{45}$ & & & & & & & \\
\hline 11 & 29 & 22 & $\underline{33}$ & $\underline{44}$ & $\underline{55}$ & & & & & & & \\
\hline 12 & 43 & 24 & 36 & $\underline{48}$ & $\underline{60}$ & $\underline{66}$ & & & & & & \\
\hline 13 & 43 & 26 & 39 & $\underline{52}$ & $\underline{65}$ & $\underline{78}$ & & & & & & \\
\hline 14 & 57 & 28 & 42 & 56 & $\underline{70}$ & $\underline{84}$ & $\underline{91}$ & & & & & \\
\hline 15 & 69 & 30 & 45 & 60 & $\underline{75}$ & $\underline{90}$ & $\underline{105}$ & & & & & \\
\hline 16 & 83 & 32 & 48 & 64 & 80 & $\underline{96}$ & $\underline{112}$ & $\underline{120}$ & & & & \\
\hline 17 & 83 & 34 & 51 & 68 & 85 & 102 & $\underline{119}$ & 136 & & & & \\
\hline 18 & 105 & 36 & 54 & 72 & 90 & $\underline{108}$ & $\underline{126}$ & 144 & $\underline{153}$ & & & \\
\hline 19 & 105 & 38 & 57 & 76 & 95 & 114 & $\underline{133}$ & 152 & $\underline{171}$ & & & \\
\hline 20 & 127 & 40 & 60 & 80 & 100 & 120 & 140 & $\underline{160}$ & $\underline{180}$ & $\underline{190}$ & & \\
\hline 21 & 143 & 42 & 63 & 84 & 105 & 126 & 147 & 168 & $\underline{189}$ & $\underline{210}$ & & \\
\hline 22 & 165 & 44 & 66 & 88 & 110 & 132 & 154 & $\underline{176}$ & $\underline{198}$ & $\underline{220}$ & $\underline{231}$ & \\
\hline 23 & 165 & 46 & 69 & 92 & 115 & 138 & 161 & $\underline{184}$ & $\underline{207}$ & $\underline{230}$ & $\underline{253}$ & \\
\hline 24 & 195 & 48 & 72 & 96 & 120 & 144 & 168 & 192 & $\underline{216}$ & $\underline{240}$ & 264 & $\underline{276}$ \\
\hline 25 & 203 & 50 & 75 & 100 & 125 & 150 & 175 & 200 & $\underline{225}$ & $\underline{250}$ & $\underline{275}$ & $\underline{300}$ \\
\hline 26 & 229 & 52 & 78 & 104 & 130 & 156 & 182 & 208 & 234 & $\underline{260}$ & $\underline{286}$ & $\underline{312}$ \\
\hline 27 & 245 & 54 & 81 & 108 & 135 & 162 & 189 & 216 & 243 & $\underline{270}$ & 297 & $\underline{324}$ \\
\hline 28 & 275 & 56 & 84 & 112 & 140 & 168 & 196 & 224 & 252 & $\underline{280}$ & $\underline{308}$ & $\underline{336}$ \\
\hline 29 & 275 & 58 & 87 & 116 & 145 & 174 & 203 & 232 & 261 & $\underline{290}$ & $\underline{319}$ & $\underline{348}$ \\
\hline 30 & 317 & 60 & 90 & 120 & 150 & 180 & 210 & 240 & 270 & 300 & $\underline{330}$ & $\underline{360}$ \\
\hline 31 & 317 & 62 & 93 & 124 & 155 & 186 & 217 & 248 & 279 & 310 & $\underline{341}$ & $\underline{372}$ \\
\hline 32 & 347 & 64 & 96 & 128 & 160 & 192 & 224 & 256 & 288 & 320 & $\underline{352}$ & $\underline{384}$ \\
\hline 33 & 371 & 66 & 99 & 132 & 165 & 198 & 231 & 264 & 297 & 330 & 363 & $\underline{396}$ \\
\hline 34 & 405 & 68 & 102 & 136 & 170 & 204 & 238 & 272 & 306 & 340 & 374 & $\underline{408}$ \\
\hline 35 & 425 & 70 & 105 & 140 & 175 & 210 & 245 & 280 & 315 & 350 & 385 & 420 \\
\hline 36 & 471 & 72 & 108 & 144 & 180 & 216 & 252 & 288 & 324 & 360 & 396 & 432 \\
\hline 37 & 471 & 74 & 111 & 148 & 185 & 222 & 259 & 296 & 333 & 370 & 407 & 444 \\
\hline 38 & 509 & 76 & 114 & 152 & 190 & 228 & 266 & 304 & 342 & 380 & 418 & 456 \\
\hline 39 & 537 & 78 & 117 & 156 & 195 & 234 & 273 & 312 & 351 & 390 & 429 & 468 \\
\hline
\end{tabular}


Military Technical College Kobry Elkobbah,

Cairo, Egypt May 29-31,2012 $6^{\text {th }}$ International Conference on Mathematics and

Engineering Physics (ICMEP-

6)

\begin{tabular}{||l|l|l|l|l|l|l|l|l|l|l|l|l||}
\hline \hline 40 & 583 & 80 & 120 & 160 & 200 & 240 & 280 & 320 & 360 & 400 & 440 & 480 \\
\hline 41 & 583 & 82 & 123 & 164 & 205 & 246 & 287 & 328 & 369 & 410 & 451 & 492 \\
\hline 42 & 641 & 84 & 126 & 168 & 210 & 252 & 294 & 336 & 378 & 420 & 462 & 504 \\
\hline 43 & 641 & 86 & 129 & 172 & 215 & 258 & 301 & 344 & 387 & 430 & 473 & 516 \\
\hline
\end{tabular}

